\title{
Identifying Morocco's Perceived Attractiveness to SMEs Managers in Germany
}

\author{
Abdallah Rhihil, Alexander Unger, Karim Gassemi, and Aicha Jellil
}

\begin{abstract}
In the age globalization, the concept of attractiveness is of crucial importance to territories that are involved in a fierce competition over attracting geographically mobile investments. Attractiveness is a new imperative for creating jobs, increasing investment in industry and services, accessing the global market, and developing new technologies. Attracting potential investors is therefore a major objective for all territories, and more specifically developing countries. The attractiveness of territories is based on a number of location advantages that are of fundamental importance, as companies only select the sites that enable them to reinforce their competitiveness. In this context, promoting and welcoming foreign investments is a multidimensional challenge in which the identification of perceived attractiveness to small and medium-sized enterprises occupies a prominent place. In this work, we discuss and explore the determinants on which foreign companies base their choice to locate in Morocco, using an analytico-descriptive research methodology as well as an exploratory study including managers and entrepreneurs from Germany. The objective of this study is to verify the attractiveness of Morocco as an economic destination especially in the strategic sectors (i.e. renewable energies, tourism, offshoring, agriculture and fishing, etc.).
\end{abstract}

Index Terms-Foreign direct investment, small and mediumsized enterprises (SMEs), territorial attractiveness, outsourcing.

\section{INTRODUCTION}

Foreign Direct Investment (FDI) is undoubtedly one of the most sought-after international investments. Despite all the noticed issues relating to how the minimum capital holding threshold is determined (the criterion for defining FDI), all definitions tend to agree on the sustainable benefit for the investing firm, notably for the SMEs [1, 2].

The inequality in the distribution of FDIs remains preeminent and this is to the detriment of the least developed countries $(3 / 4$ of the world's FDI flows are concentrated in the European Union, Japan and the United States). However, this situation is progressively changing for some developing countries mainly in Africa which are on the process of integrating the global economy. FDI has long been regarded with scepticism, but the situation has reversed since the 1980s mainly due to the failure of the advocated economic models [3].

Manuscript received January 7, 2018; revised February 18, 2018.

Abdallah Rhihil and Karim Gassemi are with National School of Business and Management of Casablanca, Morocco (e-mail: rhihilabdallah@gmail.com,k.gassemi@encgcasa.ac.ma).

Alexander Ungeris with Ludwigshafen University, Germany (e-mail: Alexander.Unger@hs-lu.de).

Aicha Jellil is with Electrical and Manufacturing Engineering Loughborough University, UK (email: A.Jellil@lboro.ac.uk).
In the current economic context, international investment is considered to be the leitmotiv of sustained economic growth, and countries, regardless of their level of development, put in place political strategies and action plans to attract these FDIs [4].

The attractiveness of a country is considered today to be an important component of economic policy. It is at the centre of promotion policies, planning and development. With the globalisation of the economy where the cost reduction in transport and telecommunication has reduced distances, companies wishing to set up operations abroad are pushing up the bidding with regard to their selection and choice of location. Thus, countries are competing more and more and doing everything possible to not only attract these investments but also retain them.

Furthermore, governments have become the promoters of their own territories in order to compete in attracting multinational companies as investment projects are very limited and the number of candidate territories is constantly increasing [5].

Driven by the positive impact that a sustained flow of FDI can bring, the Maghreb countries in particular are engaging in a real outpouring of incentives of all kinds. Morocco is no exception to this since the 1980s it initiated profound reforms in order to open up its economy to the world market. The country has solemnly announced new measures to manage investment projects in more close and decentralised manner, and this by setting up the Regional Investment Centres (IRCs) which facilitated the delegation of powers traditionally held by the central authorities to the local officials. This is in addition to the upgrading of its FDI hosting system to regional and international standards [6].

With the signing of the Association Agreement with the European Union, the United States, Turkey, China, Russia and other Arab countries through the Agadir Agreement, and its membership in the World Trade Organization (WTO) (member of the WTO since 1 January 1995 and of the GATT since 17 June 1987), Morocco has today embarked on a process of openness and unprecedented liberalization of its economy aiming to embed it in the international economy [7]. However, its production system and the content of its external trade remain of a typical developing country. This openness is believed to be fundamental as it can generate strong and sustainable growth, provided that a clear and well-structured policy reforms are rapidly and effectively implemented [8].

The net flow of FDI in Morocco has decreased to MAD 22.8 billion, approximately EUR 2 billion $(-28.2 \%$ in comparison to 2015), this decline comes after five years of steady growth. Nevertheless, the net investment in 2016 remains close to the average of the past ten years (EUR 2.1 
billion) [9].

Generally, Morocco offers foreign investors favourable economic, institutional and environmental regulations. Thus, Morocco, in comparison to other territories in the region, has undoubtedly benefited from its effort as its international investors developed a solid and intact confidence in the country. This is reflected in the trend increase in FDI in Morocco from 2011 to 2015 . The decrease of $28.2 \%$ in FDI in 2016 can be explained, in particular, by an increase in loan repayments and mergers and acquisitions [10].

The sectorial developments of FDI are inscribed in a growing attraction of the Moroccan industrial sector, to the detriment of other traditional sectors such as banking and real estate. Over the period of 2009-2013, FDI in industry has increased by nearly a factor of six. In 2015, despite a $25 \%$ decline in FDI in industry compared to 2014, the sector continues to capture a large share of FDI (18\%). The rampup of certain industrial activities such as agri-food, automotive, aeronautics and electronics has benefited the realization and implementation of large-scale operations [10].

France remains among the main investors in Morocco in terms of flows. In 2015, the biggest three investors in Morocco were: 1) the United Arab Emirates with MAD 6.3 billion (about EUR 0,6 billion), an increase of $53.6 \%$ in comparison to 2014,2 ) France with MAD 5.2 billion (EUR 0,5 billion), a decrease of $38.7 \%$ compared to 2014, and 3) the United States with MAD 3.6 billion (EUR 0,32 billion), an increase of $44.4 \%$ compared to 2014. According to the Bank of France, the stock of French FDI in Morocco amounted to $€ 9.3$ billion at the end of 2015, thus representing $57.4 \%$ of the total stock of French FDI in North Africa and $18.7 \%$ of its total FDI stock in the African continent [11].

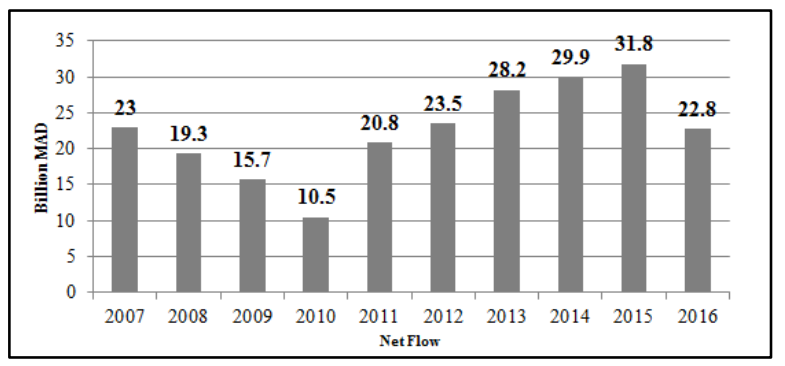

Fig. 1. Foreign Investment in Morocco 2007-2016, Adapted from: SER, Foreign Exchange Offices.

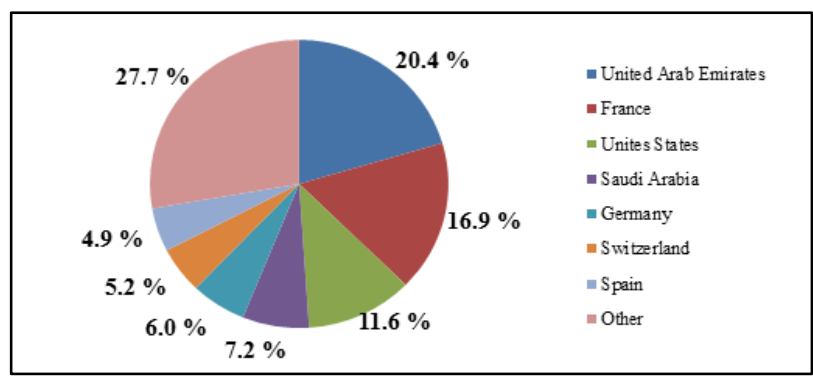

Fig. 2.Distribution of FDI flows by country in 2015, Adapted from: SER, Foreign Exchange Offices.

In terms of FDI, German direct investment in Morocco accounts for only $7.2 \%$ of foreign direct investment flows received by Morocco, and 6\% of German investment flows in North Africa. This investment amounted to $€ 118$ million in 2013, which represented only $3 \%$ of foreign direct investment flows from Germany [12]. In fact, $90 \%$ of the German yearly investment (\$10 billion) dedicated to the African continent is allocated to only three countries: South Africa, Nigeria and Algeria (Fig. 2).

\section{THE CHALLENGE}

Focusing on the elements mentioned and discussed in the previous section, this research aims to identify Morocco's perceived attractiveness to German managers and entrepreneurs. This aim is supported by the following research questions:

- Which elements dictate and influence the choice of multinational companies in locating their investment in Africa?

- What are the main economic and financial policies, as well as any other means used by governments to attract foreign investment, particularly from SMEs? What are the effects of these policies on FDI flows?

- What distinguishes Morocco and its investment promotion policy? What are the effects of this policy, particularly the legal framework put in place, on FDI flows in Morocco? Is this sufficient to attract foreign investors?

- What are the main determinants of the attractiveness of Morocco as an economic destination, especially regarding the strategic sectors of activity (i.e. renewable energy, tourism, offshoring, etc.), to German managers and entrepreneurs (with a focus on SMEs)?

\section{RESEARCH METHODOLOGY}

In line with the above defined objective, this work follows an analytico-descriptive methodology as well as an exploratory study involving German managers and entrepreneurs (especially SMEs). The aim of these studies is to examine the "Attractiveness of Morocco as an economic destination especially regarding strategic sectors (i.e. renewable energies, tourism, offshoring, industry and outsourcing, agriculture and fishing, construction, etc.)". This exploratory study will be carried out using a semistructured questionnaire including themes that characterize and relate to the attractiveness of the Moroccan offering and attractiveness.

Moreover, a literature review is conducted from the perspective of the main economic players that are interested in foreign direct investment, namely multinational enterprises. This is complemented by an analysis study of the tools and measures included in public policy development frameworks used by various territories to attract FDIs. This section attempts to identify the factors and determinants of attractiveness for different investors.

Following this, a review of the system and promotion tools put in place by public authorities in order to attract foreign direct investment, in particular SMEs, as well as the elements contributing to the attractiveness of the Moroccan offering, is completed. This enables the identification and 
examination of how Morocco is perceived in relation to its attractiveness by German managers and entrepreneurs.

An evaluation and testing of the theories drawn from the conducted analyses (the appreciation of the attractiveness of the Moroccan market by German investors) are also carried out by developing and administering a semi-structured questionnaire designed for German managers and entrepreneurs, with a focus on SMEs.

Finally, the conclusion of this study focuses on examining whether the determinants of the attractiveness of Morocco, as revealed throughout the research, are correlated and in line with the expectations and the crucial elements informing the location choice of the German investors. A discussion of this research's limitations is also provided along with the prospects for future German investments in Morocco which is expected to be offering more investment opportunities in various areas that are yet to be exploited.

\section{REFERENCE FRAMEWORK}

According to Porter [5], the competitive advantage of firms can result from two changes: i) reducing production costs through technological innovations or ii) through introduction of new factors of production, and enabling the differentiation of products by brands, advertising, etc.

As for the territories, they have comparative advantages that combine their location, their capabilities in terms of production factors (i.e. labor, capital and subsoil wealth), as well as their productivity (ratio of quantities of each factor used in production). Thus, the determinants of FDI or the factors of attractiveness of a host country represent:

- Market demand and accessibility factors (size of the host country market, geographical and cultural proximity between host and host country, density of communication networks);

- Supply and return of investment factors (wage rate, labor qualification and productivity, relative return on investment, technological capabilities of the host country).

Policies aimed at attracting foreign investment should therefore, as a priority, try to improve these macro and micro-economic factors and combine them with sound business strategies. This convergence is a major feature of globalization.

Moreover, countries wishing to attract foreign capital concentrate most of their attractiveness policy on fiscal and financial incentives. These include tax incentives such as a reduction in tax rate on profits, temporary tax exemptions, exemptions or refunds of customs duties, reductions in social security contributions, etc. Those financial incentives also consist of subsidies for the training of labor, free supply of land or installation on the site, preferential rates of water and electricity, etc. Nevertheless, examining the impact of these incentives reveals a mixed picture. Indeed, they may attract interest, but they will rarely suffice to compensate for the absence of factors such as political stability, quality of infrastructure and labor, which are considered more fundamental. Many econometric studies conclude that financial and other fiscal incentives cannot compensate for an unfavorable business environment or climate, or fundamentals deficiencies in an economy.

However, promotion policies related to foreign investments in Morocco remain marginal as many of their components require considerable adjustments and improvements (such as bureaucracy and administrative delays). Thus, implementation of texts and regulations remains insufficient to make a country more attractive to foreign investors as long as certain practices persist.

\section{Multidimensional CHARACTER OF GLOBALIZATION}

This document provides a range of concepts that we propose to clarify in a preliminary stage, which are: globalization, and multinational enterprises.

At the outset, globalization consists of three components [13]: trade flows represented by exports and imports of goods and services, productive investments that allow an enterprise to produce and distribute in several countries by relocating its production outside the country of origin, and movement of capital between the various financial centers in the world. These components have several characteristics and specificities:

- They are interdependent: the financing of a direct investment will often be through a transfer of capital from the country of origin to the country of establishment or by a loan on the international or local financial market. Often the decision of direct investment follows a practice of exporting a company to host countries;

- The power and growing influence of the actors of globalization and multinational enterprises considerably reduce the economic and interventionist powers of states.

Based on the multidimensional character of globalization, it is possible to distinguish between configurations according to a dimension's relative predominance in time. First, the configuration of the international economy, characterized by the predominance of the trade dimension, was the dominant configuration of globalization until the early 1960s. Then came the emergence of multinational economy from the sixties to the mid-1980s, when foreign direct investment multiplied alongside exports. They are the result of companies that became multinational. These enterprises have multiplied in number, they were initially of American origin, followed quickly by European companies, then later (decade 1980) by Japanese ones.

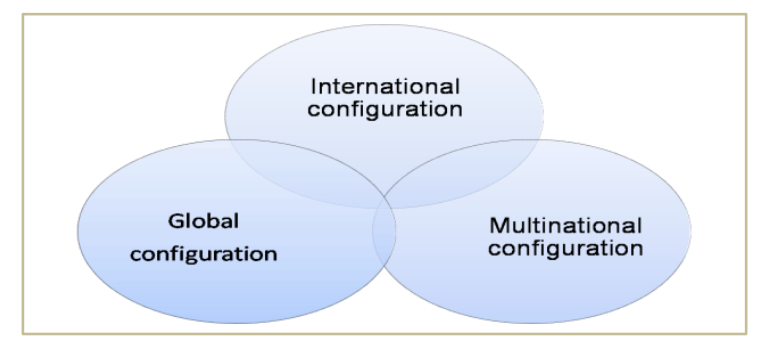

Fig. 3.The three dimensions of globalization.

Finally, since the end of the eighties, the financial and global configuration, the movement of capital and financial 
speculation, have developed. The circulation of capital as well as banks and financial institutions become of considerable importance.

As is shown in Fig. 3, based on the hierarchical interdependence of these three dimensions of globalization, three configurations can be distinguished [4].

\section{SMES: GLOBALIZATION ACTORS}

After specifying the framework of reference for the concepts used in this article through a cross - reading grid, the first results of analysis concerning the characteristics and the factors determining the attractiveness of Moroccan SMEs are briefly described. This is followed by a brief overview of German SMEs to highlight how globalization enables companies to project their subcontracting networks abroad, particularly in Morocco, while maintaining deep links with their national productive base.

\section{A. Moroccan SMEs}

The Association Agreement with the European Union, which came into force in 1996, sees, as a main measure, the creation of a free trade area between the European Union and the countries bordering the southern Mediterranean focusing on secondary and tertiary sectors. Morocco, like any other country, does not escape the requirements of the process of globalization which is governed by the law of the strongest. The country began to prepare its economy for this new deal in foreign trade which particularly affects small and medium-sized enterprises (SMEs) constituting 92\% of the Moroccan industrial fabric. All large companies, most of which have foreign ownership, are already oriented towards the European market. Priority is, thus, directed to all measures aimed at strengthening the competitiveness of SMEs.

The government is seeking to attract FDI based on the assumption that they will help create jobs and build productive capacity, bring tangible benefits, fostertechnology transfer and improve skills. This has led to the need for the development and implementation of a new adjustment plan by the Moroccan government since the early 1990s, which is concerned with both the macroeconomic and the organization of the company in order to bring it to a competitive level, and enabling it a more flexible and faster immersion in world trade.

As a result, the upgrading program in Morocco focused on the company and its immediate environment, and on technical and financial measures. The upgrading therefore took place to restructure and configure the company to modernize its operating and management methods in order to make it competent and able to cope with the openness to markets.

In order to succeed in this Moroccan upgrade, seven overarching objectives have been developed: (1) reinforcement of the reception infrastructure, (2) export promotion, (3) strengthening of professional associations, (4) establishment of a technological infrastructure, (5) intensification of cooperation between Moroccan and European companies, (6) strengthening of the financing mechanisms, and finally (7) vocational training for human resources due to the close link between the training and qualification of the workforce and the process of economic and social development.

According to Morocco-SME (formerly the National Agency for the Promotion of Small and Medium-Sized Enterprises), the number of SMEs currently in Morocco is estimated at 7262 out of a total of 7812 manufacturing enterprises, i.e. $93 \%$ of the sector [14].

These enterprises contribute positively to job creation and regional and local development $(60 \%$ of jobs in the private sector are generated by SMEs) and also to economic growth (their shares in Moroccan exports are close to $31 \%$ ). However, their contribution remains largely below the potential that this category of companies can offer, since all production units provide only $10 \%$ of the value added and only distribute $16 \%$ of the wage bill. Large enterprises which only represents $8 \%$ of the sector create $90 \%$ of value added and distribute $84 \%$ of the wage bill [15].

Thus, several measures are put in place by the Moroccan government, notably the contractual framework StateMorocco SME 2015-2020, which aims mainly at [16]:

- Reinforcing the competitiveness of ecosystems and the SMEs by leveraging operational performance, investment, creativity and co-development and access to markets;

- Promoting entrepreneurship and the development of the entrepreneurial ecosystem through the deployment of the self-entrepreneur status and the provision of accompaniment services to formalize activities;

- Creating a new generation of entrepreneurs and SMEs with a structured and high impact business model.

To better understand and analyze the situation of Moroccan SMEs, we present our preliminary results of the SWOT analysis.

Regarding the strengths, Morocco enjoys geographical proximity to Europe and political stability, and benefits from the abundance of a young active population and a liberalization of the banking sector as well as relatively low interest rates. Moreover, the private sector is evolving in comparison to the public sector.

As for the weaknesses, we notice that the average size of firms is small and the social capital is predominantly of familial nature. This is in addition to an existing management approach that is unsuited to the new demands of international trade. Moreover, there is a low productivity of the factors of production and of the internal organization of production characterized by its inefficiency. Finally, qualified and motivated human resources are often lacking in the Moroccan company.

The analysis of the current situation of the Moroccan company reveals several opportunities, including the new growth prospects with the opening of markets, the possibility of opening the capital to new partners, the knowhow of companies backed by multinationals, and the opening of Morocco to Africa and its strategic position.

As for the threats, one can decipher the rough competition even on the local market. The increase of wages not compensated by the increase of competitiveness hinders the advantage of the cost reduction. This is in addition to the low purchasing power and lack of clear social projects, and 
the gap between the speed of reform and the demand for globalization.

In the light of what has been presented, it is important to ask the question on the positioning of Morocco in relation to other countries. Moroccan performance contrasts sharply with that of other emerging market economies, which have experienced rapid growth in private investment and GDP in the 1990s. In the 1990s GDP growth per capita was on average close to 10 per cent per year in China, 5.5 per cent in India and more than 4 per cent in Thailand despite the problems they faced. These differences in growth that have been maintained over one to two decades make a big difference in living standards. Not so long ago, Morocco was much richer than China, today the real income of China is about a seventh higher than that of Morocco.

The trend noted above suggests that Morocco has lost its competitiveness compared to other emerging economies. There are large flows of foreign direct investment (FDI) all over the world, mostly in manufacturing. While China received $4 \%$ of GDP in FDI in 2000 and Thailand 5\%, Morocco received 3\% of GDP in FDI over the period 19992001, stimulated mainly by the telecoms sector [17].

The strategic development choices adopted by Morocco have placed it on the path of openness and progress. This process was intensified by the establishment of targeted sectoral strategies. In this way, the Moroccan economic sector has embarked on a dynamic of growth that has been consolidated since the implementation of the Emergence Plan and the conclusion, in 2009, of the National Pact for Industrial Emergence. To date, tangible achievements have been noted, in particular: the sector's $22 \%$ increase in exports, a marked shift in infrastructure, the establishment of global industrial leaders, and an increase of foreign direct investment (FDI) to an average annual rate of $23 \%$ since 2009 [17]. These performances have enabled Morocco to be better positioned on global radars as a credible and competitive economic destination, which is favorably located at the crossroads of Europe, Africa, the Middle East and America.

This consolidation requirement is based on three fundamental acquisitions, namely (1) the stability that Morocco can enjoy at the institutional, political and macroeconomic levels and which constitutes a valuable competitive advantage in a world in constant reconfiguration, (2) the attractiveness developed thanks to an offer combining proximity, competitiveness and access to markets, and (3) the massive efforts made in road, air, port, industrial and telecom infrastructures, which now make Morocco a multi-connected nation where movement of people, goods and data is rapid.

Changes in macroeconomic policy could certainly alleviate some immediate cost problems and help Morocco become more competitive. In the longer term, however, it would obviously be desirable to improve the productivity of firms so that higher wages go hand in hand with high competitiveness. Countries such as South Korea and increasingly Thailand have had to withdraw from the majority of labor-intensive sectors due to rising wages.

\section{B. German SMEs}

In the European Union, SMEs are of particular importance and their number is estimated to be around 21.6 million, or $99.8 \%$ of European companies, and provide 88.8 million jobs [18]. The biggest numbers of SMEs in the EU28 are located in Germany, Spain, France, Italy, Poland and the United Kingdom. The SMEs in these countries alone account for $66 \%$ of all European SMEs, for $74 \%$ of the value added generated by these companies, and for $69 \%$ of employment. Of these 21.6 million, $92 \%$ are very small companies with less than 10 employees and a turnover of less than 2 million Euros. The majority of micro-enterprises are located in countries such as Czech Republic, Greece or Slovakia. Statistics show that SMEs are responsible for more than $2 / 3$ of jobs in the European Union (around 69\%), with Very Small Enterprises VSEs accounting for $20.7 \%$, small enterprises for $29.7 \%$ and medium-sized enterprises for $17 \%$. Overall, SMEs contribute more than half of the turnover of the European private sector [18].

From 1988 to 2001, large firms contributed to job losses while the SME sector was largely an employer. In the early years of this period, growth was concentrated in the small business sector, while medium and large firms only gained momentum from 1997. In 2001, the economic slowdown negatively impacted employment in all sectors, but it is mainly the large companies that have reduced jobs through redundancies. Overall, SMEs contribute around $70 \%$ of jobs in the EU, a number that is expected to increase further due to the challenges and opportunities facing European SMEs in terms of globalization, e-commerce and the use of Internet by entrepreneurs.

Germany owes its title of world champion in exports to its countless companies from beyond the Rhine or what is known as "Mittelstand". Effectively, in macroeconomic statistics, foreign trade accounts for only one-fifth of the total turnover of these small and medium-sized companies, but one in four German SMEs is now open to the world [19].

In an interesting study of the international activities of SMEs published in 2007, The InstitutfürMittelstandsforschung (SMEs Research Institute IFM, Bonn) showed that 381,000 SMEs practice at least one form of internationalization: export, branch establishment, and / or shareholding in a foreign company. In addition, there are 41,000 SMEs making direct investments abroad and some 8,000 SMEs using all possible forms of openness to the world market. In other words, German SMEs are not limited to trade.

Obviously, the type of investment made abroad depends on the size of the company. The smallest ones clearly prefer to open a branch / subsidiary outside the borders, while those with a turnover of between $€ 10$ million and $€ 50$ million are involved in the capital of a foreign company. The development strategy of exporting SMEs, the first step towards consolidation of activities, is to open a branch or subsidiary in order to ensure the fluidity of production and trade (first imports and then exports). This allows the growth of the activities and is then extended, if necessary, by taking a stake in the capital of a company located in the partner country. This is how German SMEs pursue an organic growth strategy outside the national territory where they also export their networking mode. It naturally concerns the most efficient and the biggest in terms of turnover or workforce.

The preferred destination for these investments is the Community market where three-quarters of Direct Investment (DI) are carried out. A small fifth of the SMEs 
that opened a subsidiary or branch did so in one of the Central and Eastern European countries. A sectoral approach reveals that it is the SMEs in the industry (but also increasingly those in the services sector) that invest mostly in the current EU, a situation that corresponds to the geographical structuring of German foreign trade.

It should be added that the acceleration of globalization over time, the rapid spread of ICTs such as lower transport and communications costs, faster integration of the Community market, internal monetary stability, rapid expansion of the EU market before the enlargement of the EU to the east, as well as China's entry into the WTO, have significantly altered the situation. A number of small enterprises have declared bankruptcy [20], others have climbed into the inflation classification (nominal sales had increased while the statistical nomenclature remained unchanged). More generally, this change seems to be due to a movement of concentration; however, external growth is not enough to explain the changes observed in the structure of the Mittelstand. It is certainly in the leading sectors of the German economy, the most exporting industrial branches, that the shift has been most marked.

But these branches (chemistry, metallurgy, mechanical engineering, electro-techniques and precision mechanics) are also the most important, and therefore subject to intense competition. It is in these areas that the share of VSEs declined while that of the average entities grew. Conversely, the creation of micro-companies or micro-enterprises was multiplying in sectors that are in full development (i.e. energy).

Even if the cost factor is of some importance, it is undeniably secondary in comparison with the imperatives of growth and sustainability of activities. According to a study published by the BDI (Römer, 2007), only one-third of overseas DI follow a cost-cutting logic, while the remaining two-thirds are motivated by the conquest of new markets or stabilization of market shares. This is where one of the main reasons for the multiplication of branches / subsidiaries and investments outside Germany must be seen: they make it possible to reduce costs (transport in particular) by purchasing intermediate goods on the spot, to increase customers and margins by producing and selling products and services also on site, and to ensure the sustainability of the network of partnerships.

\section{CONCLUSION}

Noting that German SMEs are increasingly dependent on the evolution of their global environment and that no or very few studies are available to determine the determinants of attractiveness and decisive factors in the choice of locating investments in Morocco, we try to fill this gap and to better understand the nature of this fabric of companies through the elaboration of a semi-directive questionnaire for German managers and entrepreneurs in Germany. This is with the objective of checking the correlation between the expectations of future German investments and the attractiveness factors proposed by Morocco.

\section{REFERENCES}

[1] C. A. Michalet, "The seduction of nations or how to attract investments," Economica Paris, vol. 30, pp. 72-82, 1999.
[2] C. A. Michalet, "A new imperative of industrial policy in globalization: Attractiveness," in Globalisation and Economic Policy. A. Bouet andJ. Le Cacheux, Eds. pp. 383-400, 1999.

[3] World Investment Report, 2009: Transnational Corporations, Agricultural Production and Development, CNUCED, United Nations, New York and Geneva.

[4] Boissieu, "Changes in the world economy," Economic Observation Centre (EOC), Business Collection and Economic Prospect, Economica, 2000.

[5] M. Porter, "Competitiveadvantage," Dunod, Paris, 1999.

[6] The deconcentrated management of the investment, Letter from the King of Morocco Mohammed VI to the Prime Minister, January 09, 2002.

[7] M. E. Riordan, "Morocco in the world economy 1995-2010," Association of Moroccan Economists, May 1997.

[8] The Moroccan economy facing the free trade challenge, Ministry of Economy and Finance of Morocco, Directorate of Studies and Financial predict, Working Paper no 18, April 1997.

[9] Foreign Exchange Offices, Ministry of economy and finance of Morocco, 2017.

[10] World Investment report, 2016. Investorsnationality: Policy Challenge, CNUCED, United Nations, New York and Geneva.

[11] Economic Development in Africa, CNUCED, UNCTAD/ALDC/AFRICA/2016, Palace of Nations, Geneva.

[12] H. Strandell and P. Wolff, "Key figures on Europe," Eurostat, 2016.

[13] C. A. Michalet, "What is globalization?" The Discovery, Paris, p. 210, 2002

[14] Industrial Acceleration Plan, National Agency for the Promotion of SMEs in Morocco, 2017.

[15] Multinational Enterprises, Development and Decent Work: The Promotion and Implementation of the Tripartite Declaration of Principles Concerning Multinational Enterprises and Social Policy, International Labor Organization, Geneva, 2015.

[16] UNCTAD's Activities for Africa: Improving Access to Finance for SMEs in Morocco; UNCTAD, Trade and Development Board, Fiftieth executive session, 2010.

[17] Moroccan Growth Diagnosis: Identifying Morocco's Binding Constraints to Broad-Based Growth, African Development Bank (AfDB), Government of Morocco and Millennium Challenge Corporation (MCC), pp. 38-67, 2015.

[18] Annual Report on European SMEs 2013/2014: SMEs Start Hiring Again, European Commission, Internal Market, Industry, Entrepreneurship and SMEs, November 2015.

[19] I. Bourgeois and R. Lasserre, "German SMEs: Actors of globalization, insights on the german economy," CIRAC Economic Bulletin, no. 83, 2007.

[20] D. Bundesbank, AnnualReport 2006, Bundesbank, Frankfurt am Main, Germany, 2006.

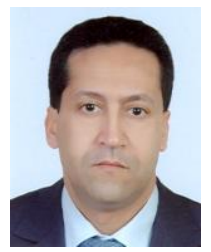

Abdallah Rhihil holds two PhDs, one is in exploitation of natural resources and the other is in modeling and environmental protection. He got a master degree in industrial and logistics management from esli REDON (France). $\mathrm{He}$ is a permanent professor at National School of Business and Management of Casablanca since 2014, where he served as a professor of project management and business management. He was also in charge of Economic Affairs and Coordination in a public authority institution. $\mathrm{He}$ is the vice president of the Network of Casablanca Associations for Environment and Sustainable Development and the vice president of International Association for Management Science and Governance. Dr. Rhihil made important scientific contributions to the fields of Quantitative Relationships Structure Activity and the exploitation of natural resources and he was asked to refer to several research works and publications. Pr. Rhihil current research focuses on entrepreneurship and the territorial management system.

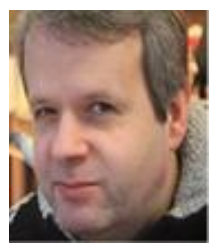

Alexander Unger is a research assistant at the University of Applied Sciences Ludwigshafen, Germany. He holds a $\mathrm{PhD}$ from University of Mannheim, Germany. The research interests of Dr. Unger are social, motivational and cross-cultural psychology including self-control, time-perspectives risk-behavior and construal level theory. He published regularly articles in international peer-reviewed journals and is a coauthor of the books Economic Psychology and Methods of Marketing Research (both in German language). He was teaching as a 
visiting professor for methods of research at PHW Bern, Switzerland in 2008. Since 2010 he has established several international research cooperation projects with China, Japan, Greece and Morocco. Since 2015 he is a cooperating member of the Personality and Social Adaption Laboratory of the Southwest-University, Chongqing, China and since 2017 he is a visiting associate professor of the Southwest-University, Chongqing, China and associate professor of the ENCG, Casablanca, Morocco. Dr. Unger is member of the American Psychological Association (APA), International Association of Research in Economic Psychology (IAREP) and the Time Perspective Research Network (TPRN).

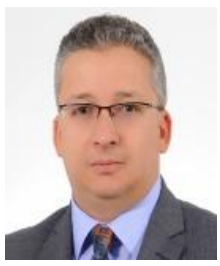

Karim Gassemi is a full professor joining the university in 2007, where he served as a professor of management and corporate strategy at the National School of Business and Management of Casablanca $\mathrm{He}$ holds a $\mathrm{PhD}$ degree from Pantheon Assas University and an MBA from Laval University. He is also in charge of the LAMSO unit research. The recipient of numerous professional awards, he has published dozens of articles. Dr. Gassemi is also the coauthor of book, "Understanding The use and development of egovernment platform in developing countries". Dr. Gassemi's recent research focuses on information system use assessment, Corporate Strategy and the Networking Performance.

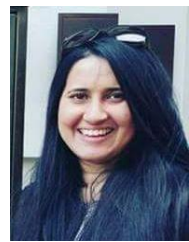

Aicha Jellil is a $\mathrm{PhD}$ student at the Centre for Sustainable Manufacturing and Recycling Technologies (SMART) at Loughborough University. Her research aims to develop strategic solutions for manufacturers and retailers to support the minimisation of consumer food waste. Previously, Miss Jellil completed her MSc in logistics and supply chain management at Lancaster University and a BSc in engineering and management sciences at $\mathrm{Al}$ Akhawayn University (Morocco). 